\title{
REVIEW
}

\section{SPECIAL REVIEW SECTION: RESEARCH PROJECTS ON SOCIAL CONSEQUENCES OF THE COVID-19 PANDEMIC}

The current COVID-19 pandemic is having a fundamental impact on everyday lives and thus profoundly shaping research in the social sciences as well. Many have denounced the crisis of social sciences in this respect, questioning their capability to generate meaning under the pandemic situation, while others have claimed the increasing importance of social sciences due to the necessity of understanding the current situation beyond its medical and epidemiological implications: i.e. the economic, political, social, and psychological impacts of the pandemic, and how people experience and cope with these. It affects the current subjects of social research whether research is focused on the (impacts of the) pandemic itself, or if the latter is taken into account as the context, while new funds are being provided for such research, and conferences organized and special issues and sections dedicated to these topics. The pandemic also affects the way research is carried out, as methodological approaches have required readjustment, whether qualitative or quantitative: face-to-face contact has been reduced, while telephone-based and online methods have thrived, increasing the opportunity for methodological experimentation, while framing old problems in a new light (for example, achieving representativity in an online survey, and how to deal with biased samples). Response rates also seem to have been affected: some respondents seem to be even more eager to share their opinions and experiences, although new issues with preselection bias may have occurred. The virus has also affected the way researchers work together, with many new forms of collaboration emerging that will ultimately advance the state of Open Science. Furthermore, the pandemic that started as an 'event' during the Spring of 2020 has become a phenomenon that has stayed with us, creating an ongoing context with an uncertain end, thus affecting the way the latter appears in social research: instead of applying event-analysis logic (measuring the situation before, during, and after the event), the situation requires consideration of the pandemic as part of the context, often altering earlier social realities and disrupting or even invalidating the continuity of data collection.

In the current issue, the Corvinus Journal of Sociology (CJSSP) acknowledges the many new research projects related to the COVID-19 pandemic in the 
Review section. In the call, we asked for short presentations of research projects at various stages - covering project objectives, the research questions/ hypotheses, the methodological approach, the kind of data being collected, sample characteristics, experiences, first results, if available, and (from an Open Science perspective) details about the eventual availability of data, together with modes of access.

In this special review section we present ongoing COVID-related research projects from Hungary and Serbia that use both qualitative and quantitative methodological approaches. Several aspects of understanding social realities are covered, including modeling of the spread of the epidemic through a survey of social interactions - one of the most important routes of transmission of COVID-19; perceptions about the virus and domestic arrangements created to cope with it; how families have been affected through an analysis of the social situation and mental health of mothers and contact between non-resident parents and their children during the pandemic; how the pandemic has affected special groups in a vulnerable situation such as international students and migrants; and how the pandemic has affected social and political participation when face-toface contact was limited. Finally, we provide an overview of further COVIDrelated research projects that were presented at a dedicated section of the "Sociology at the Dawn of a Successful Century?" conference of the Centre for Social Sciences of the Hungarian Academy of Sciences Centre of Excellence, held in October 2020 in Budapest. 